\title{
"SOB O FALSO PRESTÍGIO DO MARAVILHOSO": O ENSINO DE HISTÓRIA NOS PARECERES DA INSTRUÇÃO PÚBLICA DE 1883
}

\author{
"UNDER THE FALSE PRETEXT OF THE WONDERFUL": \\ HISTORY TEACHING IN THE STATEMENTS OF PUBLIC INSTRUCTION FROM \\ 1883
}

\begin{abstract}
RESUMO: O escopo deste artigo é a análise da proposta de História Ensinada a partir do parecer do projeto da reforma da Instrução Pública Primária, de 1882. O documento é um importante testemunho acerca dos embates sobre a renovação da Instrução Pública brasileira no último decênio do Império do Brasil, bem como de uma cultura política educacional de perspectiva liberal. Pautado no referido documento, ambiciona-se problematizar a concepção de História defendida pelos intelectuais que o elaboraram e o entendimento atinente ao lugar da disciplina História no âmbito da formação do cidadão brasileiro.
\end{abstract}

Palavras-chave: Ensino de história. Rui Barbosa. Instrução pública. História da educação oitocentista.

\footnotetext{
ABSTRACT: This article analyzes the proposal of Taught History history stemming from the statement of the project for the restoration of the primary public education in 1882. The document is an important testimony about the struggles on the renewal of Brazilian public education in the last decade of the Brazilian Empire, and also a testimony about an educational political culture of liberal perspective. Based on the document mentioned above, the text aims to discuss the conception of history defended by the intellectuals who elaborated the document and the understanding

${ }^{1}$ Doutora em História pelo Programa de Pós-Graduação em História da Universidade do Vale do Rio dos Sinos (2017). Mestre em História pelo Programa de Pós-graduação em História da Universidade Federal da Paraíba (2011). Especialista em Ciências da Religião e possui graduação em História Bacharelado (2010) e em História Licenciatura (2005) pela Universidade Federal de Sergipe (2005). Atualmente, realiza o pós-doutoramento junto ao Programa de Pós-Graduação em Educação da Universidade Tiradentes-Sergipe, como bolsista PNPD-CAPES. Pesquisadora associada aos seguintes grupos de pesquisa: Jesuítas nas Américas, Arte, Cultura e Sociedade no Mundo Ibérico (séculos XVI a XIX) e ao Grupo de Pesquisa História da Educação no Nordeste (GPHEN/Unit/CNPq).

2 Doutor e Mestre em Educação pelo Programa de Pós-Graduação em Educação da Universidade Federal da Paraíba, graduado em História pela Universidade Estadual de Maringá (2003). Professor PPG PLII e Coordenador do Programa de Pós-Graduação em Educação da Universidade Tiradentes- Sergipe. Pesquisador do Instituto de Tecnologia e Pesquisa-ITP. Membro do Comitê Científico e do conselho consultivo da Editora Universitária Tiradentes EDUNIT e EDISE. Pesquisador associado aos grupos de pesquisa: Grupo de Pesquisa História da Educação no Nordeste Oitocentista (GHENO-PB), HISTEDBR (GT-PB) é líder do Grupo de Pesquisa História da Educação no Nordeste (GPHEN/Unit/CNPq).
} 
regarding the place of the discipline history in the scope of the Brazilian citizen's formation.

Keywords: History Teaching; Rui Barbosa; Public Education; History of Education in the 19th century.

\title{
Introdução
}

\begin{abstract}
Um bem conhecido proloquio qualifica de afortunados os povos que não têm História. Analogamente, em relação ao ensino escolar desta materia caberia parodiar o adagio, lastimando a condição das creanças a cujos primeiros esforços intellectuaes fosse imposta mais esta pena, si a disciplina que sob este nome se accrescenta ao programma primario, tivesse qualquer feição de parentesco ou affinidade com a historia de que resam os nossos livros elementares: esse enredo enígmatico de datas, nomes, classificações de dynastias, narrativas esparsas de assassinio, batalhas, perfidias, execuções patibulares, que extenua a memoria sob o peso ele uma carga de factos inuteis, solicita as primeiras impressões da infancia numa direcção perigosa, transvia o juizo, superexcita a imaginativa, desfigurando os acontecimentos sob o falso prestigio do maravilhoso, semeia dos peiores preconceitos o espirito, representando a existencia do genero humano como longa successão de encantamentos, surpresas, catastrophes, onde o imprevisto é tudo, o sobrenatural se reflecte na realidade, adulterando-a, e se esquece precisamente aquillo que constitue a historia inteira: - o nexo continuo, gradual, progressivo da evolução, que tudo liga, tudo explica, e eleva a uma superioridade incomparavel acima das violencias, das conquistas, das effusões de sangue, as influencias solidas, virtuosas e energicas da paz (BARBOSA; ESPÍNOLA; VIANNA, 1883, p. 203-204).
\end{abstract}

A epígrafe deste texto é o introito referente ao Ensino de História no parecer acerca da reforma da Instrução Pública brasileira, de 1882 . O texto foi elaborado pela comissão de deputados, constituída por Rui Barbosa, Thomaz do Bonfim Espíndola e Ulysses Pereira Machado Vianna. No parecer, os intelectuais expressaram alguns dos principais desafios da História Ensinada nas escolas primárias brasileiras, como a memorização, a carga elevada de nomes, batalhas e dinastias que extenuava a memória infantil com "factos inúteis". A presença da disciplina História no ensino elementar foi apresentada como um fardo para as crianças, tendo como referência central as narrativas históricas vigentes nos manuais escolares.

Ao expressar as barreiras para o Ensino de História, os deputados acabaram construindo uma narrativa na qual elucidavam a concepção de História e sua relevância, tanto para a sociedade, quanto para a vida 
educacional. A História foi apresentada como um conhecimento necessário para a formação das novas gerações e debatida a partir das limitações que permeavam a prática de ensino da disciplina nas escolas primárias. Desse modo, o testemunho elucida a construção do entendimento vigente na época sobre o papel da disciplina no cômputo das disciplinas escolares e problematiza as estratégias de operacionalizar o seu ensino nas escolas primárias. Como elucida Carlota Boto, "os pareceres de Rui Barbosa representam para a História da Educação talvez o primeiro grande diagnóstico da situação real do ensino no país" (BOTO, 1999, p. 259).

Considerando tais aspectos, o parecer sobre o projeto de reforma da Instrução Pública, elaborado pela comissão de deputados gerais do Império, constitui um importante registro que expressa uma concepção de História Ensinada e de diagnóstico dos problemas atinente à prática docente. Tratase de um documento no qual a disciplina História é tratada no âmbito das políticas públicas, como uma questão de Estado e de fortalecimento do caráter nacional. Ao partir desses elementos, este artigo tem como fulcro a análise da proposta de História Ensinada no âmbito do referido parecer. $\mathrm{O}$ documento é um importante testemunho acerca dos embates sobre a renovação da Instrução Pública brasileira no último decênio do Império do Brasil, bem como de uma cultura política educacional de perspectiva liberal.

Evidentemente, essa cultura política educacional não pode ser vista como uma leitura de mundo exclusiva dos integrantes da comissão que elaborou o parecer. Tratava-se da elucidação de valores pautados na leitura comum de passado e no projeto compartilhado de futuro. É um projeto construído coletivamente. Como atesta a historiadora Ângela de Castro Gomes (2016), essas projeções são construções coletivas, gestadas no âmbito das práticas de sociabilidades entre integrantes de um grupo que mantém interesses afins. Deste modo, torna-se salutar pensar essa proposta investigativa não circunscrita na figura de um sujeito individual e desprovido de contato com seus pares. Pelo contrário, as propostas gestadas por Rui Barbosa, Thomaz Espíndola e Ulysses Vianna, serão analisadas a partir do confronto de ideias, de seu diálogo com outros intelectuais e lideranças políticas de seu tempo, principalmente atinente ao processo de elucidação da 
Pedagogia moderna no Brasil e difusão das ideias liberais. Neste sentido, o parecer pode ser entendido como difusor de uma cultura política educacional.

Nos últimos decênios têm ocorrido o processo de renovação dos estudos a respeito do papel exercido pelos intelectuais brasileiros acerca das questões políticas. Assim, homens e mulheres de letras passam a ser discutidos sob uma ótica que busca romper com antigas perspectivas criticadas pela produção historiográfica do século XX, como "individualismo, subjetivismo, elitismo e presentismo". Neste sentido, emergiu uma leitura respalda em "uma abordagem da história dos intelectuais, que exige reflexão sobre a própria categoria em sua historicidade e complexidade" (GOMES, 2016, p. 11).

Esse emergir dos estudos sobre os intelectuais tem como lastro as discussões proeminentes da nova História Cultural e da Nova História Política, especialmente a partir da problematização do conceito de cultura política. De acordo com Ângela de Castro Gomes,

\begin{abstract}
A cultura política foi retomada pela historiografia por permitir explicações/interpretações sobre o comportamento político de atores sociais, individuais e coletivos, privilegiando-se seu próprio ponto de vista: percepções, vivências, sensibilidades (GOMES, 2007, p. 47).
\end{abstract}

Partindo dessa acepção, é possível vislumbrar a possibilidade de entender os embates políticos em uma perspectiva que extrapole o universo partidário, ou seja, trata-se de uma discussão que possibilita a compreensão da atuação política de atores que vivem nas zonas de fronteiras, nas margens sociais, nas sombras da História. Homens e mulheres marginalizados ou silenciados pela historiografia são tomados como sujeitos da História. Entre esses grupos excluídos das assertivas historiográficas, encontram-se os intelectuais, pois, como salienta Jean-François Sirinelli, "apesar dos avanços da história política, os intelectuais continuam negados" (SIRINELLI, 2007, p. 233).

É importante ressaltar que nem todos os intelectuais foram silenciados na pesquisa historiográfica, especialmente em casos de homens de letras que tiveram uma trajetória expressamente articulada com os embates da política 
partidária ou ocuparam cargos públicos, como foi o caso de Rui Barbosa, Thomaz Espíndola e Ulysses Vianna, que ao longo de suas trajetórias quase sempre estiveram envolvidos com a política nacional, incluindo o exercício de cargos públicos no poder executivo e, principalmente, no legislativo.

Neste caso, a proposta investigativa atenta para a outra vertente. Torna-se salutar buscar outra inquietação: a atuação intelectual de homens que estavam atrelados ao campo político e como a cultura política na qual eles compartilhavam se fez presente no parecer do projeto de reforma da Instrução Pública Primária. Com isso, torna-se possível entender o papel do conhecimento histórico no processo de reinvenção de uma identidade nacional, por meio dos usos do passado na História Ensinada, possibilitando a elucidação da assertiva de Rémond na qual a "história política articula o contínuo e descontínuo, registros desiguais" (RÉMOND, 1998, p. 35).

$\mathrm{O}$ artigo foi dividido em dois momentos. No primeiro, tem-se como foco a análise dos integrantes da comissão da Instrução Pública da Câmara dos Deputados gerais que produziu o parecer sobre a reforma da Instrução Pública Primária, nos idos de 1883. No segundo momento, o enfoque recai sobre as discussões propostas para o Ensino de História nas escolas primárias, elucidando tanto as concepções de História, como as dificuldades e soluções de enfrentamento do ensino disciplina da História para crianças.

\section{1. "Cultivar e disciplinar as faculdades moraes": a comissão da Instrução Pública}

No âmbito da historiografia educacional brasileira, o parecer do projeto de reforma da Instrução Pública Primária, publicado nos idos de 1883, tem sido pensado como a avaliação do cenário educacional sob a pena de Rui Barbosa. Os demais integrantes da comissão têm sido sistematicamente silenciados como sujeitos que pensaram os problemas educacionais do período entendido por Carlota Boto como "outono do Império".

Certamente a posição de Rui Barbosa como um entusiasta com a implantação da Pedagogia moderna no Brasil, e sua inserção em defesa de um sistema educacional nacional, levou os demais membros da comissão a 
serem silenciados como sujeitos no processo de elaboração dos pareceres. De acordo com Alberto Venâncio Filho, "Ao redigir os Pareceres, Rui tinha apenas 33 anos, estava no início da sua formação intelectual, já imbuído das ideias liberais, e depois iria trilhar outros caminhos, mas o liberalismo ficará em seu espírito" (VENÂNCIO FILHO, 2007, p. 270). Neste sentido, os demais integrantes da comissão não foram considerados como coautores. Possivelmente, o fato de Rui Barbosa ter sido o relator do parecer e dos discursos terem sido pronunciados em primeira pessoa, corroborou para a desconsideração dos demais integrantes. Um exemplo disso é o artigo de Najla Mormul e Maria Machado, no qual as autoras explicitam a dualidade de autoria:

\begin{abstract}
Esse Decreto foi submetido à apreciação da Comissão de Instrução Pública, composta por Rui Barbosa, relator, Thomaz do Bonfim Spinola e Ulisses Viana. Dessa forma, Rui Barbosa teve a oportunidade de escrever os pareceres sobre a "Reforma do Ensino Primário, Secundário e Superior" (MORMUL; MACHADO, 2013, p. 280).
\end{abstract}

Os demais integrantes da comissão da Instrução Pública, assim como Rui Barbosa, eram importantes intelectuais com vínculos políticos construídos nas províncias do antigo norte. Ulysses Pereira Machado Vianna (1848-1911), havia sido presidente da província da Paraíba, entre 1878 e 1879, cargo no qual elaborou um relatório que defendia a reformulação da Instrução Pública sob os pilares da liberdade, questão central nos pareceres de 1883. De acordo com Ulysses Vianna:

Sobre a instrucção publica recahem hoje em todos os paizes
as atenções do Governo. Nos paizes regidos pelas fórmas
representativas, destinado o povo a intervir no Governo, a sua
cultura solida e regular tem sido reconhecida, como elemento
necessário para uma benéfica intervenção. As dotações às
escolas, o aperfeiçoamento dos methodos de ensino, a sua
obrigatoriedade e liberdade, os edifícios em que funccionam
as escolas e o material dellas, a formação do professorado, os
prêmios, os favores conferidos por leis, como estímulos, à
alumnos e professores, tudo tem sido empregado, de tudo
tem-se cuidado para a elevação e o derramamento da
instrucção publica (VIANNA, 1879, p. 27). História \& Ensino, Londrina, v. 25, n. 02, p. 115-137, jul./dez. 2019 
O relatório de presidente de província apresenta dados consistentes acerca da Instrução Pública no mundo ocidental da segunda metade do oitocentos. Ulysses Vianna mostrou-se como um defensor da modernização de métodos, formação docente, dos espaços escolares e da instituição de questões, como a obrigatoriedade do ensino e a liberdade de ensinar. Além disso, o presidente da Paraíba também se mostrou conhecedor dos dispêndios sobre a Educação no Império do Brasil e na Europa:

Quem conheçe a despeza effectuada com a instrucção publica na Côrte do Império, em algumas Províncias e nos paizes da Europa e em quasi todos da América, quer directamente pelo Estado, quer pela iniciativa individual, ou pelas associações humanitárias, tem certeza de que o desenvolvimento d'ella está dependente de dispêndios avultados. Não há professorado escolhido sem ser preparado d'ante-mão por escolas para isso destinadas, sem uma instrucção technica: não há bons discípulos, sem bons professores (VIANNA, 1879, p. 28).

Assim como Rui Barbosa, Ulysses Vianna também era um intelectual atento às mudanças ocorridas no universo educacional do Brasil, e em países dos continentes europeu e americano. Além disso, o relatório referente à província da Paraíba, escrito nos idos de 1879, antecipa algumas questões que seriam reforçadas e contextualizadas no parecer de 1883 , como a defesa da liberdade de ensino. Sobre essa questão, o parecer de 1883 apresenta:

A nossa commissão não hesita em declarar que abraça esta liberdade em toda a sua plenitude. Primeiramente, não crêmos na eficácia da força, para impôr, ou exterminar idéas, para impedir que o ensino se effectue na direcção das aspirações, dos sentimentos, das correntes moraes e intellectuaes, que preponderam em cada época no espirito humano. É bem digna de recordar sempre, a este proposito, aquella expansão intima, aquella eloquente conffidencia do despola cujas invasões foram, inconscientemente, no começo deste seculo, o maior instrumencto de propagação das ideias liberes pela Europa (BARBOSA; ESPINOLA; VIANNA, 1883, p. 105). 
Se as ideias atinentes à Instrução Pública aproximavam Rui Barbosa e Ulysses Vianna, o terceiro integrante da comissão da Instrução Pública tinha como principal linha de defesa o Ensino da História e o fomento ao civismo. Thomaz do Bomfim Espíndola (1832-1889), foi um intelectual que teve uma destacada produção de livros voltados para a História, Geografia e Corografia da província de Alagoas. Ele é considerado o pioneiro nos estudos históricos alagoanos (SANTOS, 2013).

Médico formado pela Faculdade de Medicina da Bahia, Thomaz do Bomfim Espíndola ocupou diferentes cargos públicos, como vice-presidente da província de Alagoas, deputado provincial e deputado geral, cargo que o levou a integrar a comissão da Instrução Pública. Paralela à carreira política, Espíndola atuou como um mediador cultural, exercendo diferentes funções como jornalista, inspetor da Instrução Pública e a docência no Liceu de Maceió, como lente catedrático de Geografia, Corografia e História.

Pode-se inferir que se tratava de um pensador da História que teve uma trajetória voltada para a difusão do conhecimento histórico no âmbito escolar, tanto por meio da publicação de manuais escolares, como por sua atuação docente e defesa do papel da disciplina História na formação das novas gerações. Essa defesa aparece na apresentação do livro "Geografia Alagoana, ou Descrição Física, Política e Histórica da Província das Alagoas" no qual ele revelou a sua concepção de História como guia para a formação moral das novas gerações ou luz que direciona ao futuro. Nas palavras de Espíndola, "[...] a história na phrase de Cicero é o facho da verdade, a mestra da vida, e, na de Lamennis, a lâmpada collocada a entrada futuro para dissipar uma parte das trevas que o envolvem" (ESPÍNDOLA, 1871, p. 1). Além disso, Thomaz do Bomfim Espíndola argumentou sobre a relevância da História Ensinada em países que deveriam ser vistos como exemplares para o Brasil.

O estudo da geographia e história do paiz natal é hoje uma necessidade reconhecida por todas as nações que podem ser indigitadas como modelos à imitação - a Inglaterra, a França, a Allemanha e os Estados Unidos do Norte - e por isso teem ellas inserido em seus planos de estudo a obrigação de enriquecer a intelligência da juventude, já preparada para a instrucção primaria, dos conhecimentos da geographia e historia natal (ESPÍNDOLA, 1871, p. 1). 
A assertiva defendida por Thomaz do Bomfim Espíndola, remete para uma importante inquietação vigente entre os intelectuais da Educação, entre o final do século XIX e o alvorecer do XX: o momento de início do Ensino da História para crianças. Percebe-se que Thomaz Espíndola defendia que o ensino da disciplina História deveria ter início já na Educação primária, como mecanismo de enriquecer a inteligência dos jovens com conhecimentos sobre a terra natal.

\section{2. "Um vehiculo de conhecimentos especiaes": a História Ensinada no parecer ${ }^{3}$}

Ensinar História para crianças e suas implicações. Essa questão foi amplamente analisada ao longo parecer da comissão da Instrução Pública sobre o projeto de reforma do Ensino Primário. O documento do parecer tem como foco o Ensino Primário, dividido em 18 capítulos, nos quais foram analisadas questões como métodos de ensino de cada disciplina, organização pedagógica, jardins de crianças, formação das professoras e escolas normais, museu pedagógico, magistério primário, administração escolar, prédios escolares e higiene escolar. Para este artigo, consideramos apenas as questões atinentes ao Ensino da História. ${ }^{4}$

As inquietações perpassaram questões como a concepção de História Ensinada e sua funcionalidade para a formação de crianças e jovens, o momento no qual a referida disciplina escolar deveria ser ministrada e o método de ensino. Todas essas questões foram analisadas a partir do cotejo com experiências de ensino vigentes em outros contextos temporais e,

\footnotetext{
${ }^{3}$ A comissão foi instituída pela Câmara dos Deputados Gerais do Império, no intuito de apreciar o Decreto n. 7.247, de 19 de abril de 1879, de autoria do ministro Carlos Leôncio de Carvalho. A comissão foi integrada por Rui Barbosa, Thomaz Espíndola e Ulisses Vianna. Nesta comissão, Rui Barbosa foi o relator. O decreto reformava o ensino primário e secundário da corte e o Ensino Superior do Império do Brasil.

${ }^{4}$ No documento há referências metodológicas para o ensino das seguintes disciplinas do ensino primário: "educação physica, Música e canto, Desenho, Lições de coisas, Língua materna, Rudimentos de ciências physicas e naturaes, Mathematicas elementares, Geographia e cosmografia, História, Rudimentos de economia política, Cultura moral e Cultura cívica".
} 
principalmente, em outros países. Aliás, a explicitação das propostas de ensino de países da Europa e da América foi o tom predominante ao longo do parecer, demonstrando uma ampla sintonia entre os embates educacionais no Império do Brasil e o de outras nações.

A primeira questão problematizada é atinente ao papel da disciplina História no âmbito escolar. A História Ensinada foi apresentada como uma disciplina que teria como mote a formação moral dos alunos, no intuito de cultivar os sentimentos e as faculdades. De acordo com o parecer:

Do mesmo modo, porém, como a admissão das sciencias physicas e naturaes no plano da escola tem muito menos por fim ensinal-a sciencia, do que dispor o espirito para ella, assim as lições de História o hão de enveredar, não tanto como um vehiculo de conhecimentos Especiaes, quanto como um meio util de cultura para os sentimentos e as faculdades nascentes do menino (BARBOSA; ESPÍNDOLA; VIANNA, 1883, p. 204)

"Um meio útil de cultura". Essa era a finalidade apontada para a disciplina História no âmbito escolar. Na concepção defendida pelos integrantes da comissão, a História Escolar não tinha como eixo formador a elucidação dos grandes episódios e as narrativas dos fatos, com a elucidação de conhecimentos espaciais, mas a formação cultural do aluno. Essa dimensão cultural perpassava pelo reconhecimento da diversidade de experiências históricas em diferentes espacialidades e temporalidades. 0 parecer também elucidava contrapontos históricos entre povos tidos como civilizados sobrepondo "selvagens e bárbaros".

Tocando a geographia, designará, numa grande esphera, os paizes habitados ou aridos, a Polynesia selvagem, a America onde a gente que emigra da Europa, succede ao gentio, que vae desapparecendo, o oriente, cheio de monumentos e povos antigos, a China civilizada e solitaria, a Africa com os seus negros, os seus arabes, os seus desertos. Os typos de homens, os monumentos, o aspecto pincturesco das regiões serão exhibidos mediante imagens, photographias, livros, objectos caracteristicos de toda a natureza (BARBOSA; ESPÍNDOLA; VIANNA, 1883, p. 206). 
Pautado na experiência de Ensino de História na Bélgica, o parecer explicita como o ensino da disciplina deveria destacar uma lógica similar a um passeio pelo mundo tido como civilizado e bárbaro, no intuito de expressar a diversidade cultural e, principalmente, racial. Para o professor caberia dizer "que todos os outros povos têm cada qual tambem a sua historia, os seus livros, os seus objectos antigos" (BARBOSA, ESPÍNDOLA, VIANNA, 1883, p. 206). A História Ensinada perpassava pela elucidação das fontes, da cultura material, dos vestígios deixados por cada sociedade.

O uso de documentos no Ensino de História dialogava com a proposta metodológica de ensino defendida no parecer, pautada no método intuitivo, que partia do conhecido para o desconhecido, do palpável para o abstrato. Em relação à História Ensinada, a preocupação em educar partindo do concreto para o abstrato pode ser ilustrado por meio da discussão sobre raça.

Para ministrar a primeira idéa sensivel de raça, poderão utilisar-se as innumeraveis espécies caninas. Exhibir-se-hão typos das raças humanas. No que respeita a estas, como ás dos cães, indagam os sabios si é possivel que todas se originem do mesmo pae. Dividam-se

as raças em nações. Empreguem-se todos os meios intuitivos imaginaveis, para fazer distinguir nitidamente os caracteres peculiares

aos povos historicos: traje, monumentos, armas, utensis, etc., como já se ha de ter procedido a respeito das nações actuaes (BARBOSA; ESPÍNDOLA; VIANNA, 1883, p. 207).

O modelo de exposição sobre as raças elucida duas vertentes que deveriam predominar no Ensino de História. A primeira consiste na busca de elementos próximos à realidade do aluno, tornando questões conceituais próximas do vivido. Questões complexas como a concepção de raça humana deveria ser norteada com o uso de paralelos, em âmbito comparativo, como a variedade de raças caninas. Partindo da observação da realidade animal, inferia-se o estímulo para se pensar a mesma questão atinente ao universo humano, em uma duração histórica. A segunda questão que perpassava pelo ensino era a ênfase em partir do conhecido para o desconhecido.

Em relação à História, isso implicava na defesa de utilizar os exemplos das sociedades contemporâneas, casos atuais para ressaltar similaridades 
com o passado. A concepção de continuidade era um elemento importante na aprendizagem histórica dos discentes. Todavia, ainda no tocante ao método de ensino, enfatizava-se a articulação entre História e Geografia, disciplinas que tinham uma dimensão moral e patriótica. Desse modo,

[...] historia, na escola, é inseparavel da geographia: ha de relacionar-se inteiramente com ella, de modo que estas duas disciplinas se communiquem incessante e mutuamente vida, apoio e luz. A sua iniciação consistirá na historia patria, e, em seu primeiro começo, na historia local. Na ordem do tempo, a historia contemporânea constituirá o ponto de partida deste gênero de lições, como se pratica na Inglaterra e noutros paizes. Na ordem da importancia, á historia moderna, especialmente á historia contemporanea, se assignará o mais amplo espaço no programma escolar. De feito, na educação commum do povo, a maior parte do cabedal instructivo da historia deve tender a preparar o cidadão para julgar as necessidades e as coisas da sua época (BARBOSA; ESPÍNDOLA; VIANNA, 1883, p. 208).

História e Geografia deveriam ser ensinadas nas escolas de forma articulada. Mas a enunciação também revela outras dimensões sobre a disciplina História: o que deveria ser ensinado. Os conteúdos históricos deveriam partir do conhecido para o desconhecido, tanto em âmbito temporal, quanto espacial. Partia-se da História Local, para a nacional, até atingir a universal. Temporalmente, privilegiava-se 0 período contemporâneo, tido como ponto de partida e, em menor escala, o moderno. Eram as duas temporalidades que deveriam nortear os programas escolares de História. Essa ênfase nos períodos recentes era justificada pela finalidade atribuída à disciplina, de "preparar o cidadão para julgar as necessidades de sua época". Essa assertiva explicita um combate ao modelo de ensino enciclopedista e erudito, com ênfase em uma proposta mais pragmática.

\footnotetext{
Attendo-se desta sorte ao empenho de inspirar o verdadeiro sentimento da historia, póde o professor, ao mesmo tempo, apparelhar, ou proseguir o ensino do factos pelo methodo anecdotico, mediante biographias, etc., escolhendo os acontecimentos, ou os personagens historicos, que possam interessar ás creanças, e evitando enumerações,

bem como as enarrações aridas, que a memoria não conserva (BARBOSA; ESPÍNDOLA; VIANNA, 1883, p. 207).
} 
A História deveria ser ensinada sob o método de anedotas, com a explanação sobre a trajetória biográfica ou de episódios tidos como relevantes e exemplares para a formação moral dos alunos. Essa dimensão da História como mestra da vida e instrumento de formação moral da população não era exclusiva dos integrantes da comissão de Instrução Pública da Câmara dos Deputados. Pelo contrário, era uma concepção compartilhada entre os principais intelectuais que pensavam a História no Brasil oitocentista, incluindo prestigiados homens de letras vinculados ao IHGB (GUIMARÃES, 1988).

Essas propostas metodológicas atinentes à História, na ótica dos autores, "exemplificam de um modo maravilhoso o curso do methodo naturalmente peculiar á cultura histórica na escola" (BARBOSA; ESPÍNDOLA; VIANNA, 1883, p. 207). É possível afirmar que o parecer apreende a História Ensinada como uma disciplina que apresenta elementos específicos para o ensino/aprendizagem, a qual, por isso, deveria ser pensada de modo a serem consideraras as suas peculiaridades no âmbito da cultura escolar. Por esse motivo, o parecer expressou a recomendação:

Para ser racional e profficuo, para encerrar effectivamente em si as qualidades de uma verdadeira cultura, este ensino está subordinado a condições imperiosas, que releva observar escrupulosamente. 1) Cumpre-Ihe renunciar ás tradições livrescas (2), repudiar o habitos de ensino mecanico, conformar-se ás leis fecundas e poderosas da intuição (BARBOSA; ESPÍNDOLA; VIANNA, 1883, p. 207).

O parecer elucida uma preocupação com a eficiência do Ensino de História, no intuito de possibilitar uma prática tida como racional e profícua, na construção cultural do aluno. Para isso, foram apontadas ressalvas atinentes a práxis pedagógica da disciplina, com recomendações para evitar aulas que fossem consideradas mecânicas, pautadas exclusivamente na memorização de livros e repetição de lições. A intuição e as anedotas deveriam se sobrepor às lições. Seguindo essas diretrizes, o Ensino da História era entendido como salutar e necessário para o Ensino Primário, pois, 
Entendido simplesmente assim, este ensino tem por seguro a sua funcção necessaria entre as materias da escola. Entretanto, a sua adequação a esta esphera de intelligencias é sumamente delicada, e encerra em si as maiores difficuldades. Por certo, si fosse tão facil, quanto parece afigurar-se a um, aliás notável escriptor contemporaneo, 'o indicar aos alumnos, sob o accumulo de factos e nomes, a sua significação moral e o seu alcance historico, mostrando no presente a progenitura do passado e o progenitor do futuro', não se póda contestar que a historia mereceria occupar um dos primeiros lagares, entre os assumptos da instrucção primaria (BARBOSA; ESPÍNDOLA; VIANNA, 1883, p. 204).

A História como disciplina escolar apresentava uma conotação específica no âmbito da Instrução Primária, sendo a responsável pela construção da significação moral e ambientação histórica das experiências humanas. O ensino no presente seria responsável por criar conexões entre o passado e o futuro, tecendo um espaço de experiência e um horizonte de expectativas (KOSELLECK, 2006), ou forjando uma leitura comum de passado e um projeto comum de futuro. A História no espaço escolar seria um instrumento de edificação e difusão de uma cultura política, de um projeto de nação. Todavia, esse processo no Ensino Primário deveria perpassar por uma disciplina agradável, atraente para os jovens e relativamente distante das preconizações da História gestada pelos acadêmicos:

\begin{abstract}
Mas precisamente as necessidades que se impõe de um modo inevitavel ao ensino elementar, de esquivar a agglomeração de nomes e factos, precisamente a multidão, a complexidade e o caracter dos elementos que concorrem para definir a acção historica e a natureza moral das entidades eminentes e dos acontecimentos consideraveis, não permittem a este ramo de instrucção essa precedencia superior na aula de primeiras letras, cujo programma não o póde receber, senão em medida relativamente modica, reservando-se á Historia propriamente dicta o seu verdadeiro logar na educação secundaria e superior (BARBOSA; ESPÍNDOLA; VIANNA, 1883, p. 204).
\end{abstract}

Ao longo da segunda metade do século XIX, uma das inquietações que perpassavam a História como disciplina escolar era em relação ao momento no qual as crianças deveriam iniciar os estudos históricos. A validade do Ensino da História era incontestável, quando se pensava no Ensino Secundário e Superior. Ao se referir ao Ensino Primário, porém a pertinência 
da presença da História não soava de modo uníssono, em decorrência de sua complexidade e, principalmente, por ter como objeto as experiências humanas de tempos pretéritos, ou seja, uma realidade não palpável e que exigia do aluno considerável poder de abstração.

Ora, esta disposição imprescindivel mal começa aos 14, ou 15 annos de idade. Até então o ensino da historia é ou mui nescio, tal qual nos livrinhos que sabemos, ou mui ridiculo, si arma a um alvo superior. Em ambos os casos é improfficuo, emquanto á cultura de qualquer das

faculdades da creança, sobre ser pernicioso, si fór enfadonho e pernicioso ainda, si prematuramente concitar paixões (BARBOSA; ESPÍNDOLA; VIANNA, 1883, p. 204).

Se a idade ideal para a introdução aos estudos históricos era entre 14 e 15 anos, qual seria a função do Ensino de História na Instrução Primária? E se os alunos ainda não tinham a habilidade de abstrair para outras temporalidades, como deveria fundamentar-se o ensino? O parecer expressa uma Pedagogia da História no Ensino Primário voltada para a construção conceitual a partir da cultura material, ou seja, a História deveria ser ensinada nas escolas primárias a partir de seus aspectos investigativos, com o uso de fontes. Nas escolas primárias, a metodologia da História aproximava pesquisa e ensino:

Na seleção obras classicas que forem dispensavel admittir, se
condemnarão inexoravelmente esses livros inimigos da
intelligencía, composto exclusivo de áridos questionários e
nomenclatura, onde a historia inteira se reduz a alguns factos
brutos, e estes mesmos a um secco enunciado, tão desprovido
de utilidade, quanto de interesse: onde se multiplicam os
pormenores ociosos, e exactamente se omittem os mais
capazes de acordar a sympathia, e estimular a atividade
mental; onde fallece do todo o colorido, a naturalidade, a
variedade, a lucidez; onde tudo se encontra, menos
precisamente o necessario, o essencial ao cultivo das
faculdades, para cuja educação o ensino da historia póde
contribuir. Na escolha dos modos de executar essa cultura, os
recursos da escola se distribuirão pela ordem do seu de
envolvimento do seu valor educativo, nesta escala: a. A
investigação pessoal do alumno. b. A palavra do mestre. c. Os
livros de leitura.
Incontestavelmente, na esphera elementar, é a lição oral o
grande elemento de fecundação de toda a cultura historica, o 
sopro vivificador desse ensino, a lição oral, com a animação, o calor, o interesse que lhe são proprios, mui superior nos seus resultados a todos os que se obtêm pelo emprego dos melhores livros (BARBOSA; ESPÍNDOLA; VIANNA, 1883, p. 208).

O método de Ensino da História na Instrução Primária foi apresentado de forma hierárquica, demonstrando a prioridade em tornar o aluno o sujeito ativo na construção da aprendizagem. Tudo deveria partir da investigação do aluno, por meio dos vestígios históricos. Era a forma encontrada para manter o colorido e naturalidade do ensino. Em segundo plano, emergia a expressão oral dos professores, com historietas, anedotas que chamassem a atenção dos alunos. A palavra do mestre deveria apresentar-se como preleções que despertassem a contemplação das biografias que pudessem ser vistas como exemplos dignos de serem seguidos. Por fim, vinham os manuais escolares, tão propalados no âmbito do Ensino Secundário, mas tidos como ineficientes no Ensino Primário. Sobre as preleções, o documento expressa:

Fallae aos vossos alumnos, fallae-Ihes muito, fallae-Ihes sempre [...]. Narrae, narrae ainda, os grandes faclos da nossa historia nacional; e, si vos sonberdes haver, todos ouvidos e olhos os vossos pequeninos ouvintes bebei-os-hão com avidez; suas almas juvenis imbuir-se-hão d'elles, ficando-lhe a lembrança profundamente gravada na memoria. Os pormenores poderão desvanecer-se; mas o essencial, o capital, o bello principalmente, o grande, o nobre, o accessivel á intelligencia e á imitação dos discípulos, isso em que, portanto, insistireis especialmente, subsistirá intacto, influindo generosos sentimentos e, o que ainda mais vale generosas acções. No começo, só a lição oral é practicavel. Mas não é unicamente nas classes inferiores que a lição oral tem a sua rasão de ser. Menor não é, talvez, a sua necessidade nas classes medias e superiores. Ja então o alumno sabe ler; póde apprender de cór; convêm, é, até, preciso que o faça, que se exerça em voar com as proprias azas (BARBOSA; ESPÍNDOLA; VIANNA, 1883, p. 208).

As preleções deveriam ser uma prática exclusiva para o Ensino de História no Ensino Primário, mas também deveriam ser exercidas no Ensino Secundário e Superior. A lição oral era vista como um método capaz de gerar sentimentos e ações, assim como estimular a aprendizagem para levar o 
aluno a voar com as próprias asas. No Ensino Primário, a narração deveria apresentar uma sequência preestabelecida.

Narrae primeiramente os factos: animae os vossos personagens; commnnicae a tudo o atractivo e o interesse da palavra; depois, quando, outrosim, houverdes envolvido no vosso colloquio, á maneira de Sócrates, as vossas caras creanças, quando as tiverdes feito falar sua vez, remettei-as então ao livro (BARBOSA; ESPÍNDOLA; VIANNA, 1883, p. 208).

A narrativa deveria ser pautada na apresentação dos fatos e personagens, de modo que as crianças fossem envolvidas pela trama histórica. O enredo deveria ser atrativo e adequado ao método intuitivo. A defesa do método também perpassou pela descrição do modelo de ensino vigente e considerado ineficaz:

\begin{abstract}
Leccionar, pois, a historia pela ordem da sua successão natural; fallar ás creanças em epochas remotas; pretender inicial-as de começo nos factos da antiguidade; tornar por ponto de partida o berço do gênero humano, como tem procedido até hoje os que asseguram á lenda biblica o monopolio dos estudos históricos na escola, é tão absurdo, quanto pretender conhecer os varios paizes, as varias nações, as varias raças que dividem o globo, antes de haver observado a raça a que pertencemos, a nação de que somos membros, a nossa terra natal (BARBOSA; ESPÍNDOLA; VIANNA, 1883, p. 205).
\end{abstract}

Igualmente, isso não implicava na metodologia de uma História ilustrativa. Pelo contrário, a proposta de ensino proposta no parecer revela uma concepção de História Ensinada pautada na investigação e no criterioso uso das fontes históricas e da construção conceitual da disciplina pelo próprio aluno. De acordo com o parecer:

O sentimento da realidade na historia póde, para o menino, derivar da idéa da historia delle mesmo. Está nas mãos do professor induzil-o a pesquizar os factos da sua vida pessoal, levando-o a entender o modo como esse passado é o que constitue a historia. Do mestre depende o impressionar-lhe a imaginação com a idéa de perquirir as origens de sua familia, a datas e os logares do nascimento e obito dos seus ascendentes, a profissões delles, os casos da sua vida, seus 
talentos, seus haveres, etc. A creança interrogará os paes. Lerá, e comparará certidões do registro civil. Possue talvez o pae documentos, objectos provenientes de longe, de que 0 menino buscará inferir as suas conclusões. Procurará meio de informar-se e cogitará nas fontes, donde poderiam derivar as informações que necessita. Póde-se contar ás creanças a historia da escola: seus fundadores, sua construcção, sua inauguração, seus planos; teve tres classes, depois quatro, mais tarde sete, para adeante dez; mostrar os papeis que consignam esses factos, discutir a sua authenticidade (BARBOSA; ESPÍNDOLA; VIANNA, 1883, p. 205).

Os procedimentos propostos para o Ensino da História coadunavam com os passos da pesquisa histórica vigente na segunda metade do século XIX, como o levantamento documental e a crítica dos testemunhos. Em certa medida, a História Escolar até extrapolava a dimensão de investigação acadêmica, pois no ensino os professores deveriam estimular os alunos a buscarem informações com pais, com o uso da tradição oral como vestígio sobre a vida dos discentes. O parecer preconizava que o docente "Excitará o alumno a interrogar os anciãos. Dará por tarefa o recolherem informações, [...]. O menino verificará que com os successos antigos recresce a difficuldade. E ouvirá contemporaneos, que narrem por ouvir, sem ter visto" (BARBOSA; ESPÍNDOLA; VIANNA, 1883, p. 205).

Em um contexto no qual os currículos escolares brasileiros ainda privilegiavam a História Universal em detrimento da História Pátria (BITTENCOURT, 1990), o currículo proposto para as escolas primárias partia da História individual do aluno. Ao elencar o exemplo do Ensino de História em Bruxelas, o parecer expressa a compreensão sobre a crítica documental no âmbito escolar:

Póde-se expor a historia, sua configuração, seus monumentos, mostrar

mappas antigos, fixar, em presença das localidades respectivas, as suas antigas trincheiras, reconstruir o bairro que precedeu os boulevards actuaes, ver, na ante-camara do burgomestre, o antigo aspedo do Senna, mandar inquerir os paes o tal respeito. O professor não enarrará elle mesmo; mandará investigar por todos os modos. Incumbirá os alumnos de fixarem uma data. Um livro de per si só não se acceitará como prova sufficiente; mas se reguererá o depoimento de pessoas que hajam sido testemunbas, 
medalhas, inscripções monumentaes, etc. Exercicios desta natureza inclinarão o menino para o verdadeiro sentimento da historia. Si o discipulo não encontrou muitos dados acerca de sua ascendencia, exponha-lhe o professor como, pelo contrario, famílias ha, em cujo seio informações taes se preservam copiosas e certas. Mostrará antigos autos, diplomas, titulas de propriedade, etc. Dirá que as cidades têm archivos, e irá visital-os. Induzirá a notar a fórma dos pergaminbos, sua vestutez, seus caracteres. Tentará decifraIlos (BARBOSA; ESPÍNDOLA; VIANNA, 1883, p. 206).

A proposta sobre o Ensino de História perpassava pelo uso de diferentes tipologias documentais, como pergaminhos, monumentos públicos, mapas, tradição oral, livros e o próprio espaço urbano. Além disso, havia a recomendação para que o professor estimulasse o cotejo das fontes, no intuito de possibilitar a crítica dos testemunhos. Tratava-se de um ensino com caráter investigativo e pouco propenso à memorização. O trato documental foi comparado aos recursos utilizados em outras disciplinas escolares:

Começará a historia pelo aspecto exterior e nomes dos seus materiaes, como se começa a historia natural colleccionando borbolêtas. Ninguem, ao parecer, reflectiu ainda em que os verdadeiros elementos da historia não consistem no facto de referir historias, mas na acquisição de noções elementares acerca dos documentos e da maneira de apurol-os. E, todavia, não podemos reunir idéas a respeito do que seja a historia, senão proporcionalmente ás que possuimos a respeito do que sejam os documentos. Em fallecendo estas noções a historia gera a fé, e prepara homem de fé; mas não produz a sciencia, nem forma homens dispostos para a sciencia. É tendo em mira a sciencia, e não a fé, que se ha de solicitar a imaginação das creança (BARBOSA; ESPÍNDOLA; VIANNA, 1883, p. 206).

O documento apresenta a História Ensinada em dualidade entre os preceitos religiosos, acríticos e edificadores da fé, e os prodígios da ciência na formação de homens críticos e capazes de usar a imaginação. A História, pautada em anedotas e análise de testemunhos, era vista como um instrumento para fomentar o fortalecimento do espirito científico no Brasil. Tudo isso deveria ocorrer evitando-se a pretensão dogmática, na qual "as licções moraes da história evitarão cuidadosamente a forma didactica. Sejam 
mais sentidas do que aprendidas pelos alumnos" (BARBOSA; ESPÍNDOLA; VIANNA, 1883, p. 209).

\section{Considerações finais}

Este artigo teve como escopo as propostas sobre o Ensino de História no parecer sobre o projeto de reforma da Instrução Pública Primária, elaborado pela Comissão da Instrução Pública, da Câmara dos Deputados, nos idos de 1883. Uma questão debatida foi em relação a autoria do documento, pois apesar deste ter sido assinado pelos três membros da Comissão, no âmbito historiográfico a elaboração do parecer tem sido atribuída, exclusivamente, a Rui Barbosa. Mesmo considerando o papel exercido pelo intelectual baiano, na condição de redator da referida Comissão, torna-se salutar perceber o quanto as ideias presentes no documento nem sempre expressam o pensamento educacional de apenas um sujeito, mas, sim, ideias compartilhadas entre diferentes intelectuais do final do século XIX, incluindo Thomaz do Bomfim Espíndola e Ulysses Pereira Machado Vianna. Ideias que em alguns casos já haviam sido apresentadas pelos referidos intelectuais em momentos anteriores à elaboração do parecer. Neste sentido, torna-se plausível propor a perspectiva de não desconsiderar a possibilidade de uma autoria coletiva do documento.

No âmbito da proposta atinente ao Ensino de História, o parecer de 1883, expressa uma concepção da disciplina escolar muito próxima aos cânones estabelecidos para a pesquisa histórica na esfera acadêmica. A História deveria ser ensinada nos moldes de como era pesquisada, com um teor crítico, pautado no uso de fontes distintas e cotejadas. O aluno do Ensino Primário deveria ter a possibilidade de estudar História não para memorizar as narrações sobre os grandes feitos, mas para aprender os fundamentos iniciais da interpretação dos testemunhos e compreender o mundo no qual se encontrava inserido. Isso implica no diálogo com pensadores da Educação do terceiro quartel do século XIX, especialmente de países europeus.

Esta é uma segunda questão presente no parecer: o recorte temporal da História Ensinada. No Ensino Primário, a História deveria partir do 
conhecido para o desconhecido, do concreto para o abstrato. Assim, no âmbito do recorte espacial, o ensino deveria ser iniciado com a História individual do aluno, adentrando a trajetória da instituição escolar e passando para a História Local. Após a inserção do aluno na metodologia da investigação histórica o ensino passaria a elucidar a História Pátria e, em menor escala, a História Universal. No âmbito do recorte temporal, o ensino apresentaria uma dimensão fortemente presentista, com a elucidação da experiência do aluno e o adensamento do ensino com ênfase para a História Contemporânea e, em menor proporção, a História Moderna.

Contudo, uma questão que perpassa toda a proposta de ensino é a elucidação de uma cultura política educacional liberal, pautada na construção da autonomia do aluno como sujeito pensante, com estímulo para o caminho da ciência em detrimento do da fé; bem como na defesa das liberdades individuais. A História no espaço escolar tinha funções de formação moral do cidadão, capaz de se ver como sujeito histórico e de respeitar as diferenças. Um projeto ousado e pautado nos valores humanos.

\begin{abstract}
A noção mais elementar na historia é a de transformação nos costumes, no aspecto geral da humanidade. O menino (que de adultos

nisto não lhe são parecidos!) nenhuma idéa tem do relativo humano. Todo o vestuário que não o seu tem-lhe ares de esdruxulo; e d'ahi vem o preconceito,.Que se oppõe á sã apreciação da historia, do mesmo modo como, na vida actual, contraria a politica progressiva. Com a precedente e combina outra noção: a idéa de continuidade. Tão lenta é a transformação, que só a longos intervallos se percebe; de um dia ao dia seguinte nunca se dão mudanças radicaes. Os factos entretecem-se nesta continuidade da vida real das gerações. Ora, para a creança, como para o homem inculto, todo o facto historico é insulado, maravilhosa toda a narrativa. Uma tal disposição de espirito não permitte apanhar a chave da historia. Privados desta chave, homens feitos, instruidos, até, muita vez, percorrerão a historia, sem deparar jámais aquillo que os refreie de se fizerem aventureiros revolucionarios. [...]. Para entender a historia, mister é de sentirmos que os homens historicos eram homens como nós (BARBOSA; ESPÍNDOLA; VIANNA, 1883, p. 205).
\end{abstract}

Sob a pena de Rui Barbosa, Thomaz Espíndola e Ulysses Vianna, a História nas Escolas Primárias deveria nortear as crianças para se tornarem 
mais humanas, capazes de entender e respeitar as diferenças e de se verem como sujeitos que também fazem a História.

\section{Referências}

BARBOSA, Ruy; ESPÍNDOLA, Thomaz do Bomfim; VIANNA, Ulysses Machado Pereira. Reforma do ensino primario e varias instituições complementares da instrucção publica : parecer e projecto da Commissão de Instrucção Publica composta dos deputados Ruy Barbosa, Thomaz do Bonfim Espinola e Ulysses Machado Pereira Vianna. Rio de Janeiro: Typographia Nacional, 1883.

BITTENCOURT, Circe Maria Fernandes. Pátria, civilização e trabalho: o ensino de história nas escolas paulistas (1917-1939). São Paulo: Loyola, 1990.

BOTO, Carlota. A escola primária como tema do debate político às vésperas da República. Revista Brasileira de História, São Paulo, v. 19, n. 38, p. 253281, 1999.

ESPÍNDOLA, Thomaz do Bomfim. Geografia alagoana, ou descrição física, política e histórica da Província das Alagoas. Maceió: O Liberal, 1871.

GOMES, Ângela de Castro. Cultura política e cultura histórica no Estado Novo. In: SOIHET, Rachel; GONTIJO, Rebeca; GOMES, Ângela de Castro. Cultura política e leituras do passado: historiografia e ensino de história. Rio de Janeiro: Faperj; Civilização Brasileira, 2007. p. 30-47.

GOMES, Ângela de Castro; HANSEN, Patrícia Santos. Apresentação: intelectuais, mediação cultural e projetos políticos: uma introdução para delimitação do objeto de estudo. In: GOMES, Ângela de Castro; HANSEN, Patrícia Santos. Intelectuais mediadores: práticas culturais e ação política. Rio de Janeiro: Civilização Brasileira, 2016. p. 5-11.

GUIMARÃES, Manuel Luís Salgado. Nação e civilização nos trópicos: o Instituto Histórico e Geográfico Brasileiro e o projeto de uma história nacional. Estudos Históricos, Rio de Janeiro, n. 1, p. 5-27, 1988.

KOSELLECK, Reinhart. Futuro passado: contribuição à semântica dos tempos históricos. Rio de Janeiro: Contraponto, 2006.

MORMUL, Najla Mehanna; MACHADO, Maria Cristina Gomes. Rui Barbosa e a educação brasileira: os pareceres de 1882. Cadernos de história da educação, Uberlândia, v. 12, n. 1, p. 277-295, 2013. 
RÉMOND, René. Uma história presente. In: RÉMOND, René. Por uma história política. Tradução de Dora Rocha. 2. ed. Rio de Janeiro: FGV, 1998. p. 13-26.

SANTOS, Magno Francisco de Jesus. A casa das Alagoas e as "cousas do passado". Revista do IHGSE, Aracaju, n. 46, p. 95-116, 2013.

SIRINELLI, Jean-François. Os intelectuais. In: RÉMOND, René. Por uma história política. Rio de Janeiro: FGV, 2007. p. 231-270.

VENÂNCIO FILHO, Alberto. O liberalismo nos pareceres de educação de Rui Barbosa. Estudos Avançados, São Paulo, v. 21, n. 61, p. 267-277, 2007.

VIANNA, Ulysses Pereira Machado. Relatorio apresentado á Assembléa Legislativa Provincial da provincia da Parahyba do Norte pelo presidente, exm. sr. doutor Ulysses Machado Pereira Vianna, em 1.o de janeiro de 1879. Parahyba do Norte: Typ. Liberal Parahybana, 1879.

Recebido em 21 de agosto de 2018

Aceito em 12 de agosto de 2019 